\title{
Statistical Research on NEET (Not in Employment, Education or Training) in a Hungarian City
}

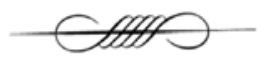

\begin{abstract}
This work is based on one of my researches that was published in Hungarian language in $2016 .{ }^{1}$

Present study focuses on young people who are NEET (Not in Employment, Education or Training) and it especially deals with the NEET population in a Hungarian city, called Szeged. This town is located in south-east Hungary, the third most populated city in the country.

In this study the author presents the number of the NEET group in Szeged, and also focuses on the qualification levels of the members of the NEET group. Both perspectives provide data and further inspiration for future studies in the country.

The research applied different statistical data sets from two informants; one of them is called Central Statistics Office (CSO), the other one is called Employment Department (ED). Both of them are located in Szeged as local organisations of their main Offices.

International data (EUROSTAT, OECD) show that the issue of NEET is a considerable problem in the European Union as well as in Hungary. Furthermore, the size of the NEET group in Hungary was higher in the research year than the average in the EU and the OECD.

The research points out that the size of the NEET group in Szeged is considerably high $(7.31 \%)$, and the rate of man is higher $(8.11 \%)$ than of women $(6.57 \%)$. On the other hand, the overall qualification level is very low within the NEET which may entail integration difficulties into employment or education in the future.

Apart from the fact that the NEET rate is fairly high in the town, it needs to draw attention to a very challenging issue due to the different measurement procedures coming from the two informants. The local ED is able to measure those members of the NEET group who are registered by the ED and also agreed to cooperate with the competent office. However, the CSO works from a survey which was generally taken in the Hungarian population. This was a census taken in 2011. Therefore, its scope was wider than the ED's. The research has shown that the local ED, which registers the members of the local NEET group, is not able to see more than half of the whole NEET population $(55.72 \%$ ) in Szeged. Thus, apart from this statistical number, we do not know more information about the greater part of the NEET group in Szeged.
\end{abstract}

\footnotetext{
${ }^{1}$ The paper was published in Hungary. SÁNTA 2016b.
} 


\section{KEYWORDS}

NEET; vulnerable youth; social exclusion; evidence based youth policies; youth protection

DOI 10.14232/belv.2017.4.4 https://doi.org/10.14232/belv.2017.4.4

Cikkre való hivatkozás / How to cite this article: Sánta, Tamás (2017): Statistical Research on NEET (Not in Employment, Education or Training) in Hungarian City. Belvedere Meridionale vol. 29. no. 4. 43-70. pp.

ISSN 1419-0222 (print) ISSN 2064-5929 (online, pdf)

(Creative Commons) Nevezd meg! - Így add tovább! 4.0 (CC BY-SA 4.0)

(Creative Commons) Attribution-ShareAlike 4.0 International (CC BY-SA 4.0)

www.belvedere-meridionale.hu

\section{INTRODUCTION}

\subsection{Objective}

This study explicitly does not introduce the concept of NEET (Not in Employment, Education or Training) nor does it focus on the NEET group generally because several international and Hungarian literatures have dealt with this subject so far, and in a former paper the author also elaborated on that (SÁNTA 2016a; See also: SPIELHOFER ET AL. 2009; COLES ET AL. 2010; SisSIONS JONES 2012).

In here it is sufficient to give a definition of NEET as a starting point for further studying of the focus group: The NEET is a separate, clearly defined and statistically measurable cohort whose members are aged between 15-24 years, and who are unemployed, they are not in the education system or taking part in any training (SÁNTA 2016a).

This study explicitly focuses on a question: What is the size of the NEET group in Szeged within the total 15-24 year-olds age group?

The paper also concentrates on the qualification levels achieved by the members of the NEET group. These data indicate the most vulnerable sub-groups in the main cohort.

The NEET issue has a huge challenge for Europe and as a member of the European Union, for Hungary as well in the 21th century (JANCSÁK 2011a; See also: KÁTAI 2006; JANCSÁK KÁTAI 2013). "Young people are one of the largest sources for Europe because they can embody everything what the future may hold" (JANCSÁK 2011a. 135.). However, young people have serious challenges to step in the labour market as well as to take part in the education or training system. The situation is no better in Hungary wherein the NEET rate is considerably high as was mentioned in one of my former studies (SÁNTA 2016a).

Dealing with the NEET issue is reinforced by researches on young people who have a vulnerable situation in the labour market and the education system. Some youth sociologists in Hungary (JANCSÁK 2013; See also: JANCSÁK 2011b; NAGY 2008; BAUER - SZABÓ 2011; GÁBOR 2012) who dealt with the problem from a youth planning point of view emphasise that "the youth 
on a shady side have been surrounded by a forest of unattainable and unrealizable opportunities" (JANCSÁK 2013. 15.). These valorise a deeper scientific understanding of the world of young people who are NEET.

However, publications which explicitly dealt with the numbers of the NEET group in towns or regions in Hungary have not been yet. This research from this approach is a pioneering work and hopefully gives inspiration for further studies in Hungary in the future.

\subsection{Hypothesis and expected results}

The research originates from a hypothesis that the rate of the NEET group in Hungary is high. This is based on the results of the EUROSTAT and the OECD (European Commission 2012, 2013, 2014; OECD 2013, 2014, 2015). In this study this hypothesis will be supported by data from the Centre Statistics Office (CSO) and also from the Csongrád County Government Office Employment Department (ED) in Hungary.

The methodological procedures of the two informants (CSO and ED) differ from each other. Therefore, it is presumable that the rate of the NEET group is higher than the rate of the officially registered NEET group. To prove this assumption Szeged was chosen, the third largest Hungarian city in terms of population (Local Equal Opportunity Programs in Szeged [LEOPiSZ] 2013). Therefore, the population of Szeged is able to provide an adequate multiplicity to define the rate of the NEET group, and possible changes in its numbers.

Presumably the expected result is that - the examined census data from 2011, and comparing this with the ED's data from the same year - the NEET group in Szeged is significant which at the same time adumbrates the situation of the NEET issue in Hungary. That means, I assume that the results of the research show that both participation in the labour market and the education and training situations are unsatisfactory for the young people, aged 15-24 living in Szeged. It may entail serious consequences from a Social Policy point of view.

\subsection{Short description of the methodology}

The research is basically quantitative. Two datasets were used: the CSO's census data from 2011 and also the ED's data from its database. The last one points out one of the limitations of this research: only those members of the target group were derivable from the ED's database who were registered in this competent office. That means, the data from the ED's database will not provide the whole number of the NEET group in Szeged from the examined year comparing this with the CSO's database which was more accurate. Thus the consequences from the ED's data will only serve as a benchmark. The next chapter discloses the database, and also presents the limitations of the research and the detailed methodology.

In the main chapter that includes the analysis of the data set created by the author, statistical tables and diagrams will show the data in order to get a more picturesque appearance. For this propose a table of the NEET database was constructed, and this is suitable for displaying data as well as comparing the data from the two informants. 


\section{Methodology}

\subsection{Why Szeged? - a topic delineation}

Several issues were taken into account when I decided that the research within the NEET group would be limited for the city of Szeged. Introducing these criteria justify the methodological procedures.

It was mentioned earlier that the population of Szeged provided sufficient statistical multitude in order to begin the research within the subject. Being a local citizen also made the research for me more convenient.

However, the basic starting point was that I did not find a comprehensive research which would specifically address the NEET problem. The research material which would have worked up a certain area, region or even nation-wide database was not found. Thus the applied methodology is inductive, that is, the research is organised from the smaller units to the overall picture. After processing and evaluating the data in Szeged there will be a possibility of widening the picture of the research towards the entire NEET population in Hungary. My plan is to continue county-level research followed by processing data from neighbouring counties in this direction, which will be finalized by a regional research. This would be followed by the introduction of additional regions as well as a comparison of regions in the light of the NEET population data. The final plan is to prepare a nationwide NEET-map which specifically depicts the boundaries of the vulnerable and less vulnerable areas. So in this sense the present research is a pre-research into a deeper and more complex data processing.

A deductive method is, I think, not an appropriate starting point since nation-wide data do not reflect on different regions and it does not reflect on the unusual specificities of different counties even cities either. However if the aim is to terminate or at least to reduce the NEET problem with action plans, it is necessary to take into account the different features of the individual areas. Because what is the real goal? To reduce (or to terminate which would be the best) the size of the NEET group, to support each member of the group to be able to reintegrate into the world of the labour market and the education and/or training. This work can be successful if, after processing the data, the members of the NEET group are personally visited, and they are supported by complex, personalized programs (or action plans) in order for them to reach the final goal. This can be, I think, facilitated by detailed, inductive research series.

\subsection{Description of the informants}

The size of the NEET group in Szeged is derived from the data of the Centre Statistics Office (CSO) and also from the Employment Department of the Csongrád County Government Office (ED).

It would have been extremely beneficial to obtain the size of the NEET group from the census data in the period since the change of the political system; however, it was not doable. Although figures of three censuses were available but the processing of the first two, the census data from the 1990 as well as 2001 could not be taken into account. The reason is the following: when these two sets of data were taken there were no questions concerning the presentation of the portfolio of the NEET group. From the first and the second census I could only procure the data of the total 15-24 age group. However, this data set will be referred to in the next chapter. From the data 
of the last census conducted in 2011 the size of the NEET group in Szeged can be derived, thus this is one of the reference points that enables me to compare the data.

The other data set has been compiled from the database of the ED. Those data also show the size of the NEET group in Szeged from 2011, of course with the difference that the database of the ED is able to present only those young people registered at the Department.

\section{2.a Methodological differences between the two informants}

The CSO as well as the ED keep count the unemployed in Szeged split them up also by age groups from which the NEET group can be analysed that is, not only those who are unemployed but those who at the same time do not take part in education and/or training. However, it needs to be noticed that they have a very different methodology to determine the data, which also affects the size of the NEET group in Szeged.

According to the CSO, unemployed who did not work during the given week (does not have a work status which (s)he was temporary absent from); (s)he was inseek of a job actively during the four weeks preceding the survey; (s)he is available that means (s)he can start to work within two weeks, if (s)he could find a suitable job (NFSZ).

The CSO in its concept distinguishes between unemployed and non-employed. Giving a definition at the latter one is the best if the employed is defined. According to the CSO, every person is employed who worked in the period under review at least one hour which provided an income, or (s)he was absent from work (because of annual leave, sick leave, etc.) temporarily (NFSZ). That means, non-employed are those who are not included in concept phrased above. This information is important to know because from this distinction I was able to determine the size of the NEET group in Szeged. This is the rate of the non-learner and non-employed within the population, that is, the NEET group. Within this, it is necessary to distinguish the group of non-learner unemployed. The result of the group's breakdowns is that there are two different groups between the NEET. One of them is those who are NEET but they are looking for jobs actively (non-learner unemployed). On the other hand, there is a group whose members are also NEET but they are not in search of jobs at all (non-learner non-employed). These two groups within the NEET can possibly be identified with those who were mentioned as 'open to learning' and 'sustained' NEET in the paper of SPIELHOFER ET AL. (2009).

The ED in its system uses registered job seekers instead of unemployed as I have already referred to it. Among these criteria the most important factor is that job seekers are those who are registered by the ED and they cooperate with the Department (NFSZ). That is, a member can only be part of the NEET group if (s)he is registered as a job seeker and cooperates with the ED.

It may follow that presumably the rate of the NEET group is higher than the officially registered NEET group by the ED in Szeged. This is due to the fact that there can be some young people who belong to the NEET group, however, for some certain reasons, they do not want to be registered by the ED. If the data show this, it is possible that some of those who are not registered get the necessary income from the grey and black economy to support their own existence. This can be a new area for further research from the point of view of either Social Policy or Social Psychology or of a combination of these two. 


\section{2.b Data of the CSO}

The data of the CSO were collected from the Department of Szeged. The census data were from 1st of October, 2011. Three groups were from it. The first one is the total population of Szeged which can be compared with the same kind of data from previous censuses. It made it possible to reflect on trends. The second one is the total population of 15-24 age group and in here I was also able to provide some important findings. Finally, the third one is the rate of the NEET group in Szeged, and as mentioned earlier, only the latest census could be supported with available data. For all examined groups the gender breakdowns are nominated specifically.

The other database that comes from the CSO is the data on the educational achievement of the NEET group. There are four different subgroups in there: 1. Elementary school grade 8 or lower. 2. Secondary school without graduation but with professional diploma. 3. Secondary school graduation. 4. Degree of a higher education. These data also come from 2011.

\section{2.c Data of the ED}

The data of the ED were also collected from its Szeged branch. The statistics related to December of the current year. I examine the NEET group from two different aspects in this case. On one hand, the size of it was researched between 2011 and 2014. On the other hand, the educational achievement was examined within the NEET group from the period of 2011. The ED's data between the period of 2012 and 2014 are used only for indicative information.

\subsection{Methodology of data comparison}

A detailed comparison of the evaluated data will be introduced in five steps which indicate the direction of this research methodology as well.

In the first step, the census data of the CSO are processed. I describe the total population of Szeged and its reduction trend in table and bar chart, after that, the total population of 15-24 yearolds age group and its trend. I think the presentation of these data is necessary before I turn to introduce the size of the NEET group in Szeged. Within this data I mark the previously distinct sub-groups who are actively looking for jobs and those who are not doing so for some reasons.

In the second step, I present the data of the educational achievement coming from the census data of the CSO. Tables and bar charts are also used and the gender breakdowns are highlighted.

In the third phrase of presentation of data I introduce the data of the ED for the NEET group.

And in the fourth step, I present the data of the educational achievement coming from the ED's data. The information relating to these data are more detailed comparing with the similar data of the CSO thus a deeper view can be gained into the educational achievements of the target group.

In the final step, the data are compared with each other. I will show from this process the size of the NEET group in Szeged, its composition furthermore I will make statements about the educational achievements of the target group. 


\section{Analysis of the data}

\subsection{Analysis of NEET data based on the CSO}

The presentation of the data begins with the population of Szeged. This city is the third largest one in terms of its population (LEOPiSZ, 2013). It can be called 'University town' because the University of Szeged, with its several faculties and trainings, tends to attract young people from the whole country.

Table 1 shows the population of Szeged based on the last three censuses data. It also illustrates the numbers of men and women in the town.

\begin{tabular}{|l|c|c|c|}
\hline \multicolumn{1}{|c|}{ Censuses } & Men & Women & Total \\
\hline 01/Jan./1990. & 81,791 & 93,510 & 175,301 \\
\hline 01/Febr./2001. & 77,496 & 90,777 & 168,273 \\
\hline 01/Oct./2011. & $\mathbf{7 7 , 3 0 1}$ & $\mathbf{9 0 , 7 4 7}$ & $\mathbf{1 6 8 , 0 4 8}$ \\
\hline
\end{tabular}

TABLE 1 The population of Szeged and its gender breakdown based on the censuses data (capita). (Source: SÁNTA 2016b)

The table shows that the population of Szeged was decreasing continuously during the 21 years when the censuses data were taken. Compared to the initial data, can be seen dramatic drop in the data collection in 2001 . The population of the city decreased with 7,028 people compared with the data in 1990 . However, the rate of decline has slowed down by 2011, and the decrease was only 225 people.

The rate of men, within the population of the city, was continuously reducing. Between the first and second census the men's population decreased from 81,791 to 77,496, which means the men's population declined all together with 4,475 capita. According to the last census data, the decrease of the men's population has slowed and their number settled in 77,301. For women, the process of decline can also be observed although this is not as rapid as for men. The initial data was 93,510 capita and for the next census the population of women declined with 2,733 capita. After, the next ten years the decrease of their population was only 30 thus the women's population settled in 90,747 capita in 2011.

Figure 1 [See next page.] presents these data. The bar chart distinguishes between men, women and the total, and uses different colours: men are represented with blue, women are with purple and the total is with white colour.

It can be observed from the diagram that the rate of men is significantly lower than the rate of women. Men who claimed themselves to be resident in Szeged in 2011 were 13,446 less than women in the same year. Furthermore the number of men decreased at a higher rate than the women. Although the number of men was continuously decreasing and the rate of them tendentiously lower than the women's rate nevertheless the men's population is much higher within the NEET group than the women's population, as it will be pointed out later.

Table 2 [See next page.] presents the whole population of 15-24 year olds in Szeged according to the CSO's data. 


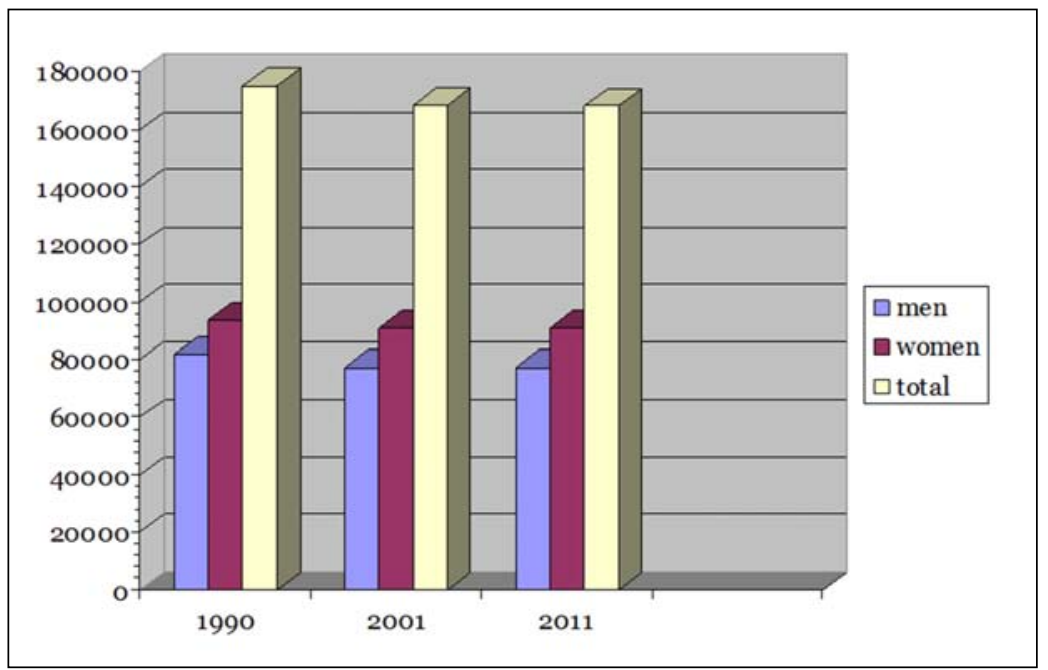

FIGURE 1 The population of Szeged and its gender breakdown based on the censuses data (capita). (Source: SÁNTA 2016b)

\begin{tabular}{|l|c|c|c|}
\hline \multicolumn{1}{|c|}{ Censuses } & Men & Women & Total \\
\hline 01/Jan./1990. & 14,345 & 15,684 & 30,029 \\
\hline $01 /$ Febr./2001. & 14,572 & 16,431 & 31,003 \\
\hline 01/Oct./2011. & $\mathbf{1 2 , 7 8 2}$ & $\mathbf{1 3 , 8 9 3}$ & $\mathbf{2 6 , 6 7 5}$ \\
\hline
\end{tabular}

TABLE 2 The whole population of 15-24 year olds in Szeged based on the censuses data (capita). (Source: SÁNTA 2016b)

It can be observed from the numbers that between 1990 and 2011 the population of the 15-24 yearolds decreased with 3,354 young people. Thus, there is a significant reduction in the number of this population. Although, between 1990 and 2001, this population did not decrease; rather it increased. The growth was 974 people thus the total reduction was 4,328 people. In the examined year the whole 15-24 year old population in Szeged was 26,675 people.

In gender breakdown, the following can be observed. The men's population between 1990 and 2001 slightly increased, with 227 capita. By 2011, this population fell to 12,782 people altogether, so the total decrease was 1,790 young people. As for women a certain amount of increase was experienced between 1990 and 2001. From 15,684 to 16,431 which was 747 women increase. However, their population also decreased by 2011 , and the value stayed well below the initial data; the total was: 13,893 . In case of this gender the decrease is higher than the men's; the number of women aged 15-14 decreased with 2,538 capita between 2001 and 2011. Although the reduction of women's population was higher than the men's nevertheless the numbers of women stayed higher than of men, with 1,111 capita.

Figure 2 with reference to the table, shows the whole 15-24 year-olds population in Szeged. This, as with the previous, uses different colours for distinguishing the genders and the total population. 


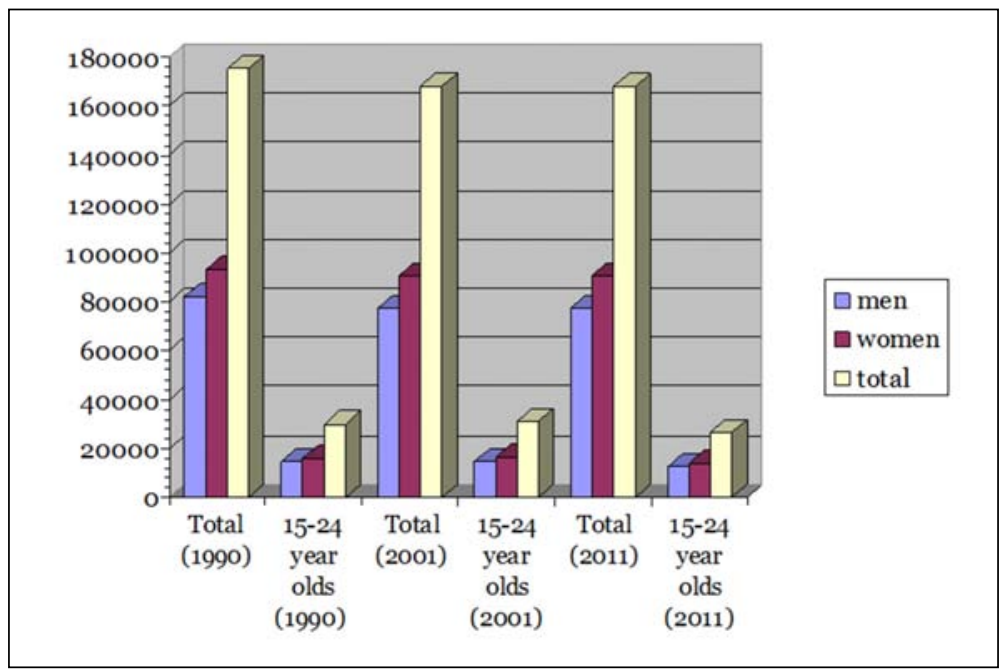

FIGURE 2 The whole 15-24 age group compared with the total population of Szeged based on censuses data (capita). (Source: SÁNTA 2016b)

In addition, each 15-24 age group from different census years stands beside the total population of Szeged from those particular census years. It can be observed that the number of total 15-24 age group slightly increased in 2001. However, the population reduced by 2011 below the rate of 1990 .

If we compare the data of the two populations with each other it can be observed that the rate of the 15-24 year-olds population of the total Szeged population was $17.12 \%$ in 1990, this rate increased up to $18.42 \%$ by 2001 . However, this trend somewhere between 2001 and 2011 stopped even the rate of the 15-24 population reduced below the rate of 1990 by the research period under the investigation. In 2011 the 15-24 year old age group was only $15.87 \%$ of the total population of Szeged.

As was mentioned earlier, different trends of the NEET group were not detectable from the censuses data because it was impossible to derive the size of the NEET group from the former two censuses data. However, an important conclusion can be made: the whole population of Szeged keeps decreasing just like the population of the 15-24 age group within the total Szeged population. The rate of this decrease is higher than within the total population. That means, in this study only one data will be presented about the NEET rate in Szeged. However, this may adumbrate a dark picture about the NEET situation. Even if we assume that the size of the NEET group in Szeged will be unchanged, that means, will not increase, the situation is still problematic because the total 15-24 age group keep reducing and the NEET group can be found within this population.

Closing this section the NEET rate in Szeged will be presented based on the census data from 2011 .

\begin{tabular}{|c|c|c|c|}
\hline Censuses & Men & Women & Total \\
\hline $01 /$ Oct./2011. & 1,037 & 914 & 1,951 \\
\hline
\end{tabular}

TABLE 3 The NEET population in Szeged and the gender breakdown based on the census data (capita). (Source: SÁNTA 2016b) 
The research year was October, 2011. The month needs to be stressed. This is due to the fact that later when the ED's data will be presented and compared with the CSO's data, it will be shown that the data come from the same year (2011). However, while the CSO presents data from October until than the ED's data come from December of the same year.

The table shows that according to the CSO's census data 1,951 young people aged between 15 and 24 were NEET in 2011. That means, these youngsters were not in employment, education or training.

Based on the gender breakdown it can be observed that the men's rate is higher than the women's. 1,037 young men were NEET in Szeged, in 2011 compared with 914 young women who were in the same vulnerable group.

Figure 3 shows the same rate in bar chart.

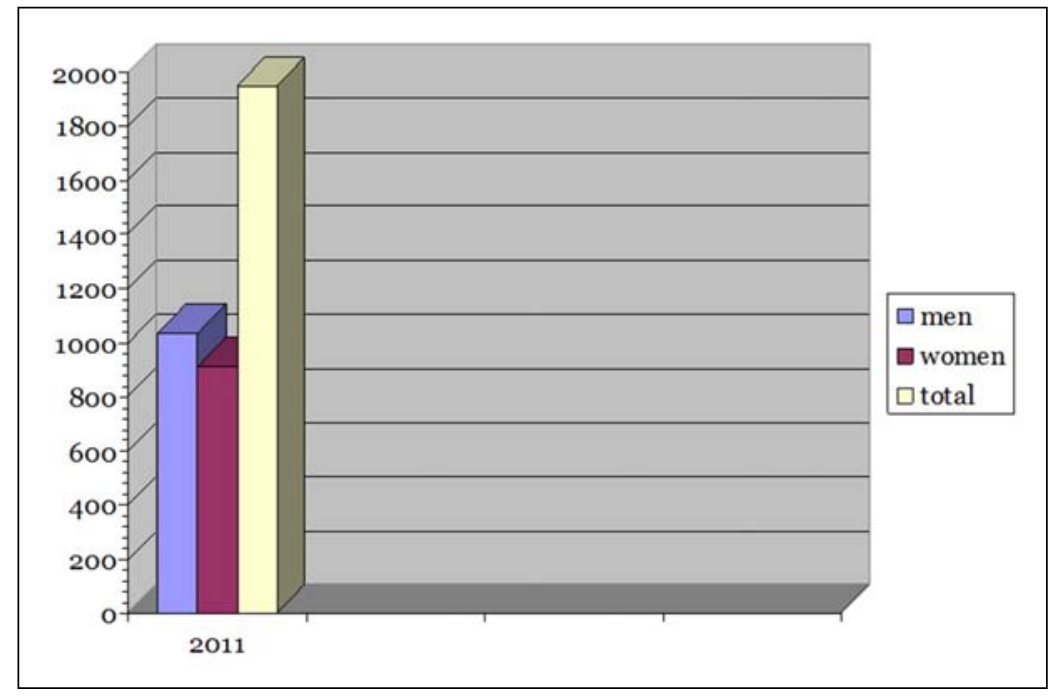

FigURE 3 The NEET population in Szeged and the gender breakdown based on the census data (capita). (Source: SÁNTA 2016b)

The chart graphically depicts that the rate of men is higher within the whole NEET population than the rate of women in Szeged. The size of men is $53.15 \%$ of the total NEET population while the size of women is $46.84 \%$. So the men's group within the total NEET population is higher by $6.31 \%$ than the women's group despite the fact that the size of men within the whole population of Szeged and even in the total 15-24 population in the city is significantly less than that of the women.

The CSO's data of the NEET group in Szeged can be divided into further two groups. The study has already mentioned that within the NEET rate in Szeged two sub-groups can be distinguished: those who are NEET but actively looking for jobs, and those who are also NEET but for certain reason(s) they are not searching for jobs. The first sub-group can be called non-learner unemployed. The other sub-group can be called non-learner non-employed. For the sake of simplicity the study hereinafter calls the first sub-group job-seekers and the second sub-group non-job-seekers. The next table and diagram show the rate of these two NEET sub-groups. 


\begin{tabular}{|c|c|c|c|c|c|c|}
\hline & \multicolumn{3}{|c|}{ NEET job-seekers } & \multicolumn{3}{c|}{ NEET non-job-seekers } \\
\hline Censuses & Men & Women & Total & Men & Women & Total \\
\hline 01/Oct./2011. & 482 & 427 & $\mathbf{9 0 9}$ & 555 & 487 & $\mathbf{1 , 0 4 2}$ \\
\hline
\end{tabular}

TABLE 3.A Job-seekers and non-job-seekers NEET population in Szeged and their gender breakdown according to the census data (capita). (Source: SÁNTA 2016b)

It can be seen from the table that 909 young people who are NEET try to find jobs while the majority of young people $(1,042)$ who are also NEET do not search for jobs. In addition, it stands out that in both groups there are more men than women, does not matter whether they are job-seekers or non-job-seekers. Furthermore, 555 young men are non-job-seekers and this rate is higher with 73 young men than the other group wherein the young men who are NEET believe that if they look for jobs then this search will be successful. This is true also for women in this sense; 487 women turned away from job search and their number are 60 more than those women who were job-seekers.

The associated diagram shows the two sub-groups (job-seekers and non-job-seekers) and the total NEET group in Szeged, and also their gender breakdown.

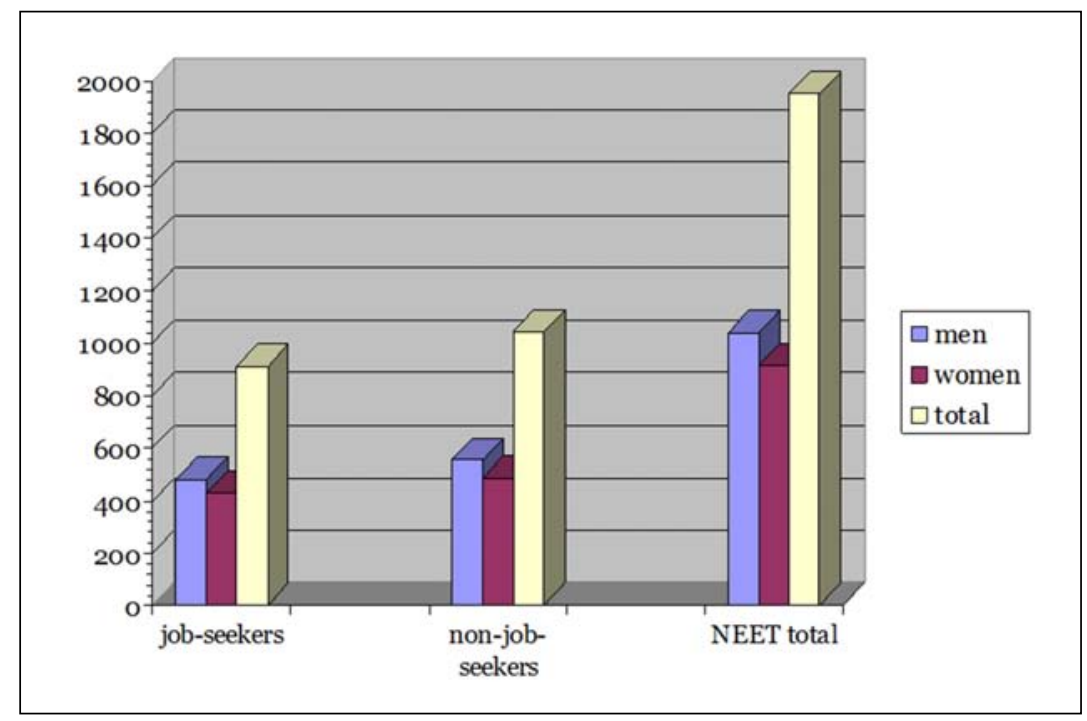

FIGURE 3.A Job-seekers, non-job-seekers and the total NEET group in Szeged, and their gender breakdown according to the census data (capita). (Source: SÁNTA 2016b)

The charts show that the rate of non-job-seekers NEET is higher than the job-seekers NEET rate. Within the total NEET population $53.40 \%$ are those who are non-job-seekers NEET while the rate of young people who are job-seekers NEET is much less (46.59\%). The men in all three groups are more than women. Within the job-seekers NEET group the men's rate is higher with $6.05 \%$ than the women's rate. Interestingly, within the non-job-seekers NEET group the men's rate is also higher than the women's rate with $6.53 \%$. 
What could be the reason that there are more young people are in the non-job-seekers NEET subgroup than are in the job-seekers NEET sub-group within the total NEET group in Szeged? One of a possible answer perhaps can be found in the eclipse of hope. Those young people are less in numbers who believe that their job-seeking action will be successful in the future.

In summary of this section, the total 15-24 age group in Szeged is compared with the total NEET group in the town. The aim of this study was to answer the question: What is the size of the NEET group in Szeged within the total 15-24 year-olds age group? The next table and diagram presents the answer of that question.

\begin{tabular}{|c|c|c|c|c|c|c|}
\hline & \multicolumn{3}{|c|}{ Total 15-24 age group } & \multicolumn{3}{c|}{ Total NEET population } \\
\hline Censuses & Men & Women & Total & Men & Women & Total \\
\hline 01/Oct./2011. & 12,782 & 13,893 & 26,675 & $\mathbf{1 , 0 3 7}$ & $\mathbf{9 1 4}$ & $\mathbf{1 , 9 5 1}$ \\
\hline
\end{tabular}

TABLE 4 The total 15-24 age group in Szeged compared with the total NEET group in Szeged and their gender breakdown according to the census data (capita). (Source: SÁNTA 2016b)

Table 4 shows that the size of the total 15-24 age group in Szeged was 26,675 young people in 2011. Within this group almost two thousand young people were not in employment, education or training that is, they were NEET!

This is a further question why the size of men, compared with the size of women, is higher despite the fact that within the total 15-24 population, there are fewer men by 1,111 people than women in 2011.

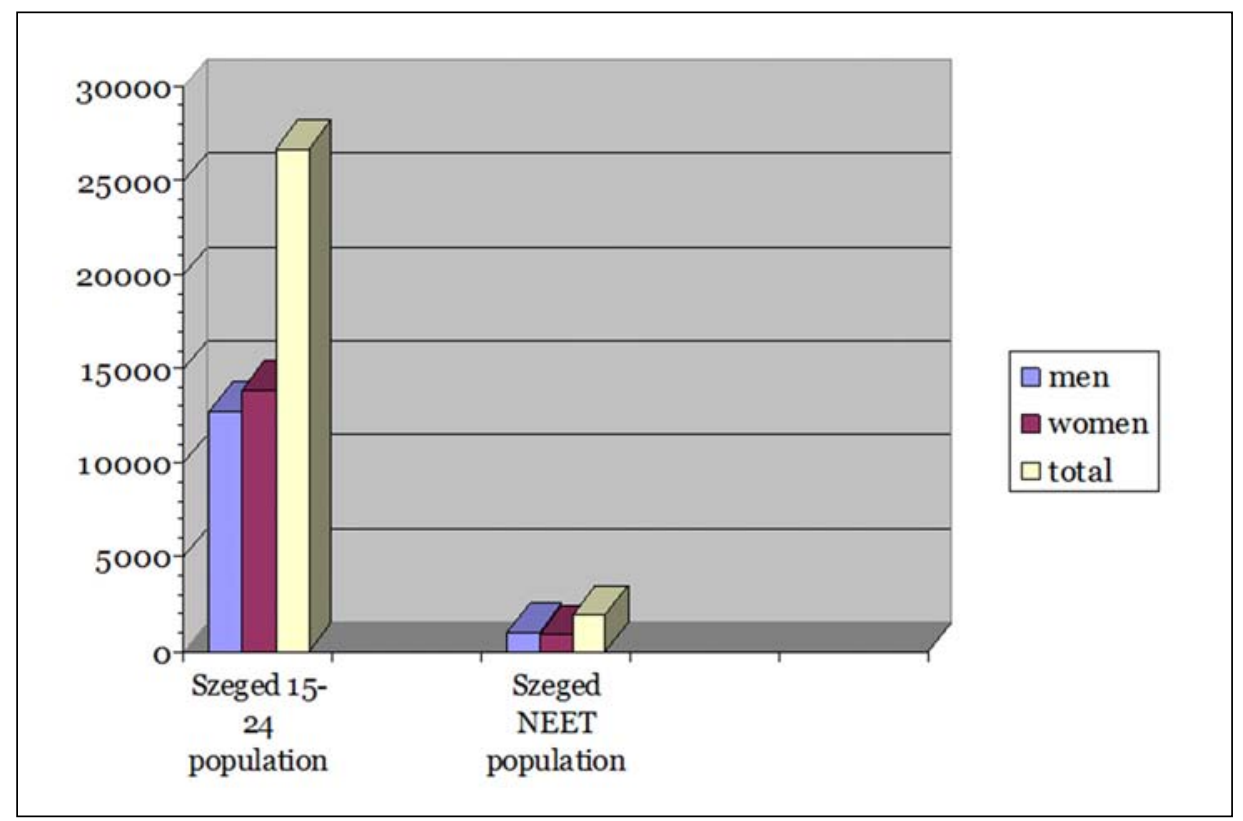

FIGURE 4 The total 15-24 age group in Szeged compared with the total NEET group in Szeged and their gender breakdown according to the census data (capita). (Source: SÁNTA 2016b) 
From the diagram, it can be observed that in Szeged the NEET population is $7.31 \%$ of the total 15-24 age group in 2011. The NEET women's rate is 6.57\% while the NEET men's rate is $8.11 \%$ in the total 15-24 population. So the men's rate was about one and half percent higher than the women's rate within the total 15-24 age group in the research year.

In possession of these data the question is answered. The size of the NEET group in Szeged was 1,951 capita in 2011 according to the census data. This is $7.31 \%$ of the total $15-24$ population who lived in 2011 in the town. This percentage is very significant in a city that its population is the third largest in Hungary (LEOPiSZ 2013); many university faculties are available, and there are renowned education and training systems; therefore, it can be assumed that the number of available jobs is satisfactory.

In the next part the census data provided by the CSO will be examined further but the study focuses on the qualification levels achieved by young people who are NEET.

According to the CSO's data the education levels can be divided into four parts in Hungary. The first part is the primary education (grade 8) and in this category those can be found as well who have not even reached this level of education. The second part is the secondary education without school leaving examination but young people with this level of education have a professional diploma. The third category is the secondary graduation, and the last part is the higher education level. Table 5 shows data concerning the number of NEET young people falling into the different categories in 2011.

\begin{tabular}{|l|c|c|c|c|c|c|c|c|c|c|}
\hline & \multicolumn{2}{|c|}{$\begin{array}{c}\text { Primary } \\
\text { and less }\end{array}$} & \multicolumn{2}{|c|}{$\begin{array}{c}\text { Secondary with } \\
\text { professional diploma }\end{array}$} & \multicolumn{2}{c|}{$\begin{array}{c}\text { Secondary } \\
\text { graduation }\end{array}$} & \multicolumn{2}{|c|}{$\begin{array}{c}\text { Higher } \\
\text { education }\end{array}$} & \multicolumn{2}{|c|}{ Total } \\
\hline Censuses & M & W & M & W & M & W & M & W & M & W \\
\hline $01 /$ Oct./2011. & 342 & 231 & 216 & 133 & 418 & 437 & 61 & 113 & 1,037 & 914 \\
\hline Total & \multicolumn{2}{|c|}{573} & \multicolumn{2}{|c|}{349} & \multicolumn{2}{|c|}{855} & & 174 & \multicolumn{2}{|c|}{1,951} \\
\hline
\end{tabular}

TABLE 5 The achieved qualification levels of the NEET group in Szeged and their gender breakdown according to the census data (capita). ( $M=$ men, $W=$ women) (Source: SÁNTA 2016b)

The table shows the different education levels and the gender breakdowns in those different categories. Men's number can be seen on the left hand side while the women's number can be seen on the right hand side. In the last line the total number of the NEET group in different education levels appear.

The numbers of men in every category are higher than the women's except the last two categories. Those who have secondary graduation (this is called gymnasium) and those who have further education level deviate from this 'trend', and in these the women's rate are significantly higher than the men's rate. Nearly twice as many women are in the NEET group who have higher education level than men; 113 women are in proportion to 61 men.

It is also important to emphasize that the highest rate appears amongst those who have secondary graduation. 855 young NEET people have this type of qualification that approximates to the half of the total NEET group in Szeged. Those are positioned on the second place who have primary education or even less (573). This is also extremely high, and these two categories highlight the levels of vulnerability as well. It seems there are two really vulnerable groups in the total NEET group in Szeged. In one of them there are those who have a very low qualification level and in the other one are those youngsters who try to participate in the world of employment with secondary graduation. 


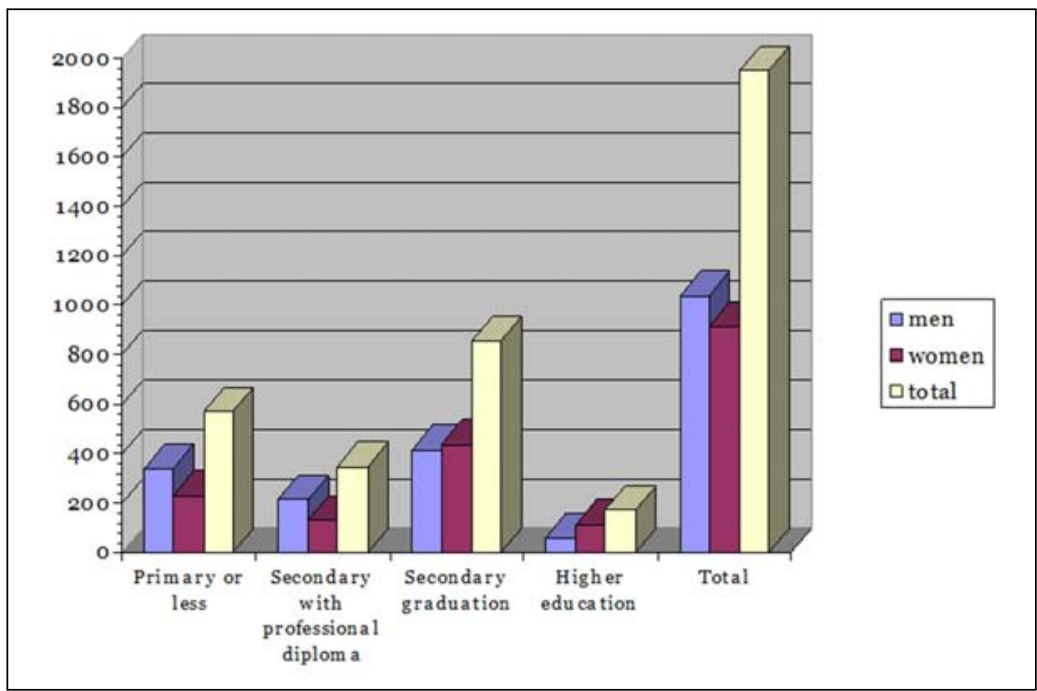

FIGURE 5 The achieved qualification levels of the NEET group in Szeged and their gender breakdown according to the census data (capita). (Source: SÁNTA 2016b)

On the diagram it can be seen more clearly that those have the lowest rate who have the highest educational level. This rate is $8.91 \%$ of the total NEET group. This relatively low rate may show that NEET young people, who have the highest education level, are more likely to be able to find a job than those who have lower qualification levels. This dataset seems to correlate with the similar British data in this breakdown (Audit Commission, 2010).

Those groups appear really vulnerable - as was already mentioned above - whose members have secondary graduation, and also those communities whose members have only primary education or less. Within the total NEET population in Szeged $43.82 \%$ have secondary graduation, and $29.36 \%$ have a very low qualification level.

Closing this section, a complex table (Table 6) will be presented for the different qualification levels however, in there the job-seekers and the non-job-seekers young people are also distinguished.

\begin{tabular}{|c|c|c|c|c|c|c|c|c|c|c|c|}
\hline & \multicolumn{2}{|c|}{$\begin{array}{l}\text { Primary } \\
\text { and less }\end{array}$} & \multicolumn{2}{|c|}{$\begin{array}{l}\text { Secondary with } \\
\text { professional diploma }\end{array}$} & \multicolumn{2}{|c|}{$\begin{array}{l}\text { Secondary } \\
\text { graduation }\end{array}$} & \multicolumn{2}{|c|}{$\begin{array}{l}\text { Higher } \\
\text { education }\end{array}$} & \multicolumn{2}{|c|}{ Sum } & \multirow[t]{2}{*}{ Total } \\
\hline & $\mathbf{M}$ & W & $\mathbf{M}$ & W & $\mathbf{M}$ & W & $\mathbf{M}$ & W & $\mathbf{M}$ & W & \\
\hline Job-seekers & 116 & 69 & 121 & 57 & 200 & 213 & 45 & 88 & 482 & 427 & 909 \\
\hline Non-job-seekers & 226 & 162 & 95 & 76 & 218 & 224 & 16 & 25 & 555 & 487 & 1,042 \\
\hline Sum & 342 & 231 & 216 & 133 & 418 & 437 & 61 & 113 & 1,037 & 914 & 1,951 \\
\hline Total & \multicolumn{2}{|c|}{573} & \multicolumn{2}{|c|}{349} & \multicolumn{2}{|c|}{855} & \multicolumn{2}{|c|}{174} & \multicolumn{2}{|c|}{1,951} & \\
\hline
\end{tabular}

TABLE 6 The qualification levels of the NEET group in Szeged distinguished in there the job-seekers and the non-job-seekers and their gender breakdown according to the census (Census 01/Oct./2011.) data (capita). (Source: SÁNTA 2016b) 
It can be observed in this more detailed breakdown that the number of men in most categories is higher than the number of women. This 'trend' is changed in the category where the NEET young people have higher education, and this change is significant in this respect.

Furthermore, it can be seen that the number of non-job-seekers in total is higher than the number of job-seekers. However, it comes to light from the examination of the sub-groups that amongst those young men who have secondary education with professional diploma and those who have higher education try to find a job despite their NEET status. 121 young men who have secondary graduation with professional diploma look for a job while 95 young men who have the same qualification level are not in search of a job. However, conversely in this category 76 NEET women decided not to go for a work while 57 NEET women try to find it actively. This result is interesting when examining the data however, that is more understandable that within those, either NEET young men or women, who have higher education, there are more who would like to get a job than those who made an opposite decision. Perhaps, this highlights the fact that young men who has vocational education, and those who have the highest qualification, believe that they will have a job in the near future. However, those who have the lowest qualification or even do not have this one, and those who have secondary graduation are probably less confident that their job search will be successful.

The diagram which relates to Table 6 shows these data in bar charts. Under the bar charts the plus $(+)$ or the minus $(-)$ indicates the job-seekers and non-job-seekers groups. Thus there are 11 bar charts all together. The last bar chart on the right hand side shows the rate of the total NEET group in Szeged.

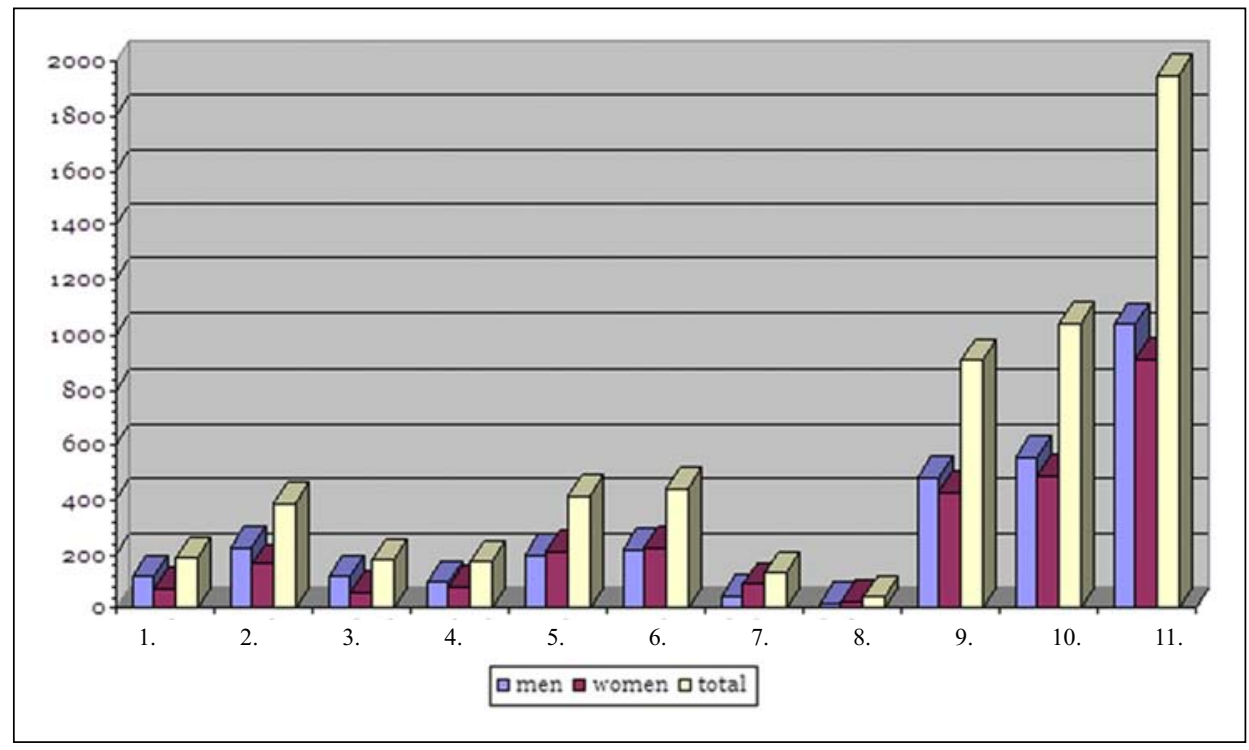

FIGURE 6 The qualification levels of the NEET group in Szeged distinguished in there the job-seekers and the non-job-seekers and their gender breakdown according to the census data (capita). [Legend: 1. Primary or less (+), 2. Primary or less (-), 3. Secondary with professional diploma (+), 4. Secindary with professional diploma $(-), 5$. Secondary graduation $(+), 6$. Secondary graduation $(-)$, 7. Higher education $(+), 8$. Higher education $(-)$, 9. Sum $(+)$, 10. Sum (-), 11. TOTAL] (Source: SÁNTA 2016b) 
There are two very vulnerable groups can be seen within the NEET group: one of them are those who have primary education or less, and the other one are those who have secondary graduation. In the group where the NEET young people have the lowest qualification level $66.08 \%$ of men and $70.12 \%$ of women belong to the non-job-seekers' group. The proportion of those who have only secondary graduation (which means have only a school leaving examination) somewhat less but more than half of both, men and women, $(52.15 \%, 51.25 \%)$ do not look for job opportunities.

However, amongst those men who have secondary education with a professional diploma (but do not have school leaving examination) and the number of those (men and women) who have higher education is proportionally higher than the numbers of job seekers. In the first category, $56.01 \%$ of men look for job opportunities but in the case of women, this process is the opposite; $57.14 \%$ of women decided not to look for a work and only $42.86 \%$ of women are the rate of active job seekers. In the second category, who have higher education, the rate of both (men and women) is higher who are job seekers (73.77\% men and $77.87 \%$ women) comparing with those who have the same level of qualifications but do not search for work.

Closing this part of the study, as a summary it can be said about the CSO's data from the 2011 census: The size of the NEET group in Szeged was 7.31\% of the total 15-24 age group in the city in 2011. Within the NEET group, the men's rate is higher $(8.11 \%)$ than the women's rate $(6.57 \%)$ despite that the men's rate is much lower than the women's in the total 15-24 population.

It is also evident that within the NEET group the rate of non-job-seekers is higher $(1,042-909$; $53.40 \%-46.59 \%$ ). This is a phenomenon that justifies a deeper social policy research in the future.

In a detailed examination of the qualification levels of the NEET group, it can be observed that there are two groups at considerable risk amongst the already vulnerable NEET group. One of them is those who have very low qualifications or even do not have any qualifications, and also those who have secondary graduation (in other words: who have school leaving examination without a professional diploma with it). In this segment it can also be observed that the rate of NEET men is higher than the NEET women's rate. Even, those men's rate is higher who do not look for jobs regardless of their already acquired qualifications (53.51\%). There was only one group as an exception where the men's rate in the job seekers category was higher than the men's rate in the non-job-seekers category. They were those who do not have school leaving examination but have a professional diploma (secondary education with a professional diploma). In this group $56.01 \%$ of men were active NEET job-seekers. In this category there were more women who did not search for job opportunities $(57.14 \%)$. As well as amongst those who have the highest qualification levels, both men and women, there were more active NEET job-seekers.

\subsection{Analysis of NEET data based on the ED}

Before the data analysis undertake it is important to mention the different data recording time and methodology of the Employment Department (ED) compared with the CSO which will appear in the figures.

The ED's data regarding to NEET group was taken in December 2011. If they compared with the CSO's data it can be observed some months differences between these two. That is, the research year is the same however the ED's data came from different month. Furthermore, the methodologies of the two informants also differ from each other as it was mentioned earlier. In here it is enough to be referred to this above mentioned analysis that the ED counts only those 
young people who are officially registered as job seekers at the Department. They can be only part of this category (registered job seekers) if the young people officially registered and at the same time they are not participant in any education or training system; that means, they are NEET.

There is another important derogation needs to be highlighted. The ED in its data do not count with the total 15-24 age group rather the Department defines three different sub-groups within the NEET group: 1.18 years of age and under; 2. 19 year-olds; 3. 20-24 age group. Compared these with the CSO's data it shows a considerable differences. Having a conversation with a colleague at the Employment Department, the above mentioned first sub-group (18 years of age and under) approximately includes the 17-18 year-olds young people. On the other hand, these sub-groups categories used by the ED provide further research opportunities in the future. Making close examinations on the different sub-groups may indicate those youngsters who are at a considerable risk within the vulnerable NEET group.

The above mentioned differences indicate that it needs to draw attention to the data recording time which was take in October 2011 by the CSO but, by the ED, was taken in December 2011. The NEET group is not a homogeneous group the members in there are continuously changing. Some changes might have been occurred between these two months in 2011; the exact data for that cannot be determined. On the other hand, the size of the NEET group in Szeged according to the ED's data is surely lower than the CSO's data. This one comes from their different methodology system, and also from the fact that the ED does not process the whole 15-24 age group.

The next the ED's NEET data will be analysed taking into account of these above mentioned differences between the two informants.

The first table in this section, which will be the seventh in the row, presents the size of the NEET group and its gender breakdown in Szeged according to the ED's data.

\begin{tabular}{|l|c|c|c|}
\hline No. registrants in closing day & Men & Women & Total \\
\hline December/2011. & 462 & 402 & 864 \\
\hline
\end{tabular}

TABLE 7 NEET population in Szeged, and its gender breakdown according to the ED's data (capita). (Source: SÁNTA 2016b)

Table 7 shows that 864 young people were registered as job seekers in December 2011 in Szeged, that is, members of the NEET group. As has been also observed by the CSO's data, according to the ED's data as well the men's rate is higher than the women's rate with 60 young people within the NEET group. Therefore, it can be stated that the NEET men group in the city is at a considerably higher risk than the NEET women group in the research year. Because their size is higher within the NEET group although the number of men were less in the population of Szeged as well as in the total 15-24 age group comparing with the number of women, and the men's number reduction appears tendentious.

The Figure 7, relation to this table shows these data in bar charts according to the ED's data. Just as it was presented above, the diagram displays the gender breakdown of the NEET group as well.

The men's rate is $53.47 \%$ within the NEET group while the women's rate is $46.53 \%$. So the Employment Department keeps count of fewer members in the NEET group in Szeged comparing with the CSO's data however, it can be said as well that the numbers of men are higher than the numbers of women. 


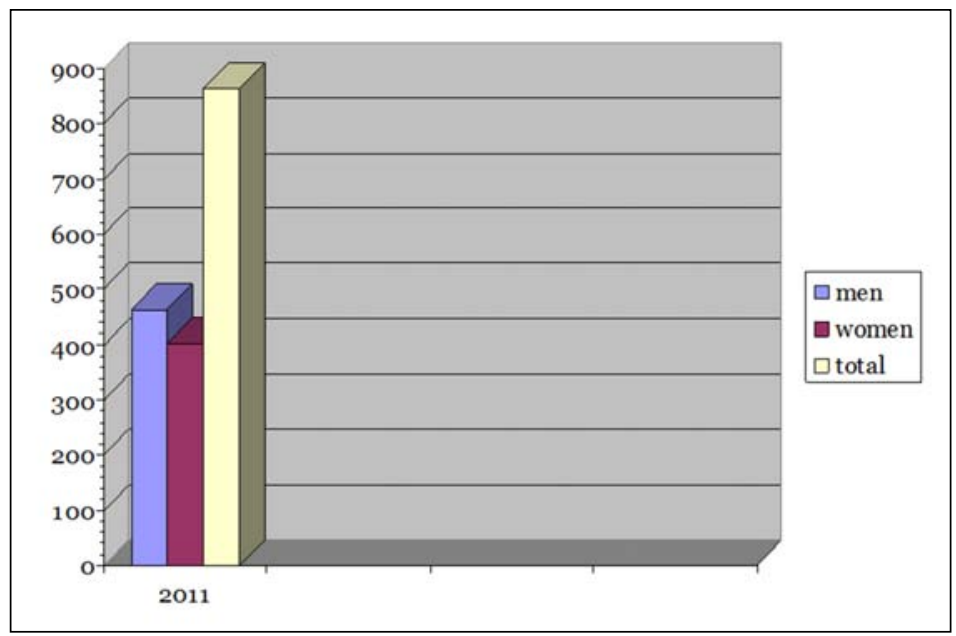

FiGURE 7 NEET population in Szeged, and its gender breakdown according to the ED's data (capita). (Source: SÁNTA 2016b)

The ED applies data recording annually and provides statements from them. Thus the data of the NEET groups in Szeged are not only available from 2011 but can be collected from the past periods till 2014. The next table and the adherent figures show those data.

\begin{tabular}{|l|c|c|c|}
\hline \multicolumn{1}{|c|}{ No. registrants in closing day } & Men & Women & Total \\
\hline December/2011. & $\mathbf{4 6 2}$ & $\mathbf{4 0 2}$ & $\mathbf{8 6 4}$ \\
\hline December/2012. & 539 & 457 & 996 \\
\hline December/2013. & 337 & 379 & 716 \\
\hline December/2014. & 374 & 339 & 713 \\
\hline
\end{tabular}

TABLE 8 NEET population in Szeged, and its gender breakdown according to the ED's data (capita). (Source: SÁNTA 2016b)

As it can be seen the data came from December 2011, and the Department used the same months from the next three years as well. It can be observed that between the research year and 2012 the size of the NEET group increased significantly. 864 young people were NEET in 2011 but this number increased and by 2012 reached 996. This meant 132 capita growths.

After this year however, a significant decrease can be experienced in numbers, and this process although more moderate pace but also continued in 2014. By 2013 the size of the NEET group in Szeged reduced with 280 capita and altogether the size of the NEET group was 716. In 2014 this reduction process was continued, and the Department registered only 713 young people NEET from this year.

In the rate of men and women the same tendency can be observed, although it is interesting that the rate of men increased more than the rate of women in 2012. In this year the number of young men NEET increased by 77 while of young women NEET increased by 55 . The next year, 2013, 
is remarkable because investigating the data from the four years, as well as reflecting on the CSO's data this is the only year when the rate of men is lower than the rate of women. 337 men were NEET in 2013 compared with 379 women. However, the 'usual order' once again returns in 2014; the number of men increase and their numbers exceed the numberof women and also exceed their own previous rate, and the men's group increased to 374. The number of women however decreased, thus a slight further reduction can be observed within the total NEET group in Szeged.

Figure 8 shows these changes in the usual way; men and women are represented with different colours as well as the total NEET population.

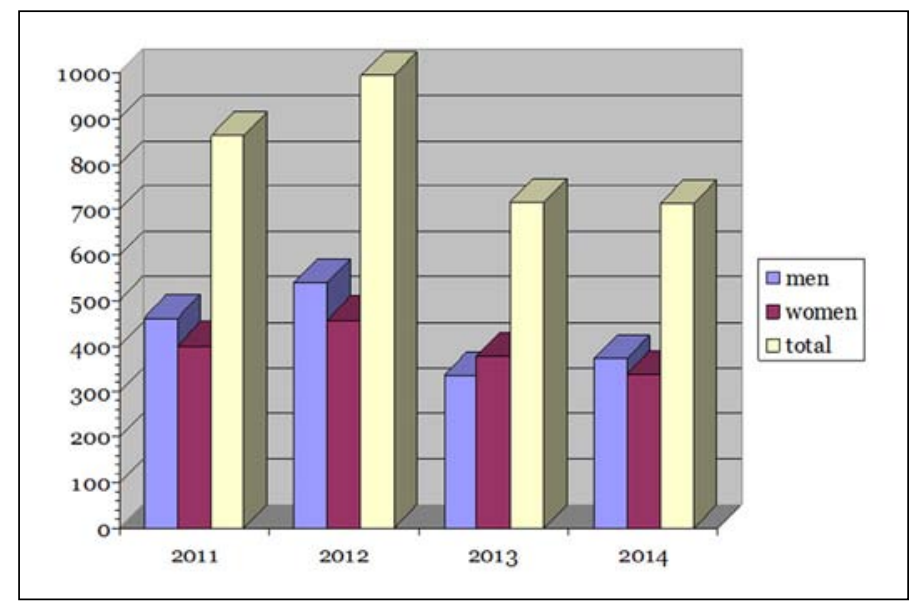

FIGURE 8 NEET population in Szeged, and its gender breakdown according to the ED's data (capita). (Source: SÁNTA 2016b)

The bar charts show that comparing the baseline data with the data from 2012 the rate of the NEET group significantly increased. The growth was $13.26 \%$ in the total rate, and within this the men's rate increased by $14.29 \%$ while the women's rate increased by $12.04 \%$. However, in 2013 a significant reduction can be observed within the total NEET rate. The total number in the NEET group decreased by $28.12 \%$ compared with the previous year. Furthermore, the men's rate in 2013 shows a significant decrease, and with this reduction at the first time the rate of women NEET exceeded the rate of men NEET. Within the total NEET rate the number of men shows $37.48 \%$ decrease, while the reduction in the number of women was only $17.07 \%$. In the next year, 2014, the men's rate increased drastically again compared with the women's rate which rate, compared it with the previous year, decreased. In 2014 the men's rate increased with 9.9\% while the women's rate decreased with $10.56 \%$. Thus it emerged within the total number of a minimal $0.42 \%$ reduction.

Further researches can prove why a significant increase was in the number of the total NEET group in Szeged in 2012 according to the ED's data as well as further investigations are able to show the reasons of the following decreases too. In addition it would be worthwhile to examine in the future what happened in 2013 when the number of men, at the first time this year, and according to the recent research so far also the last time, was lower than the number of women. It will be referred to this train of thought in the conclusion.

Returning to the main purpose and to the research year, closing this section the data of educational achievements within the NEET group in Szeged will be presented according to the ED's data. 


\begin{tabular}{|l|c|}
\hline \multicolumn{1}{|c|}{ Educational achievements } & Total/capita \\
\hline Less than primary level & 8 \\
\hline Primary education level & 250 \\
\hline Trade school level & 114 \\
\hline Professional school level & 28 \\
\hline Vocational secondary school level & 236 \\
\hline Technical school level & 27 \\
\hline Grammar school level & 156 \\
\hline College level & 26 \\
\hline University level & 19 \\
\hline Total & $\mathbf{8 6 4}$ \\
\hline
\end{tabular}

TABLE 9 Educational achievements within the NEET group in Szeged according to the ED's data (capita). (Source: SÁNTA 2016b)

It is immediately apparent that the ED publishes the qualification levels in more detailed breakdown compared with the CSO's methodology; however the Department does not publish the gender breakdowns within these levels.

Nine categories are distinguished by the ED. The lowest levels are distinguished into two parts, one of them is the primary education level and to the other one those NEET people who do not even have this lowest level of qualification. In relation to all data it can be observed that the number of those who practically do not have adequate qualification level according to the Hungarian labour market conditions is significantly high. They are altogether 258 young people within the NEET group according to the ED's data.

The next category is the so-called secondary education which is divided by the ED into further five categories. The total number of these five categories is the highest, 561 young people, within the total NEET group. Within the secondary education category three sub-categories can be distinguished: 1. provides just a profession to the young people (trade school and professional school). 2. provides a profession with school leaving examination (vocational secondary school and technical school); 3. provides only school leaving examination (gymnasium) and this level of qualification predestines the young people to continue their study in further education. Thus 561 young people can be divided into the following proportions: 142 young NEET people have a profession but do not have school leaving examination with it. 263 young NEET people have both, a profession with school leaving examination. While 156 young NEET people have only school leaving examination which would be the highest level within the secondary education but only in the case of youngsters wanting to move further into college or university. (Interestingly in Hungary if young people decide not to engage in higher education with this qualification level, this third category becomes almost the lowest one compared with the other two or better to say not worth as much as the other two.) 
The nine categories are closed with the higher education level. This sub-category is also divided into two parts. One of them is the college level with 26 young NEET people, and the other one is the university level with 19 young NEET people in the research year.

Interesting to see that amongst the data four extremely high numbers can be found, each of them are more than 100 people. While in the remaining five categories the number of registered young NEET people is infinitesimal. The most young NEET people in terms of their qualification level are in the primary education level, altogether 250 people. They are followed by the secondary school level (236), those who have a profession and also a school leaving examination. On the third place are those who have only school leaving examination (gymnasium), altogether 156 people. The line is closed by those who have trade school level, which means, they have a profession without school leaving examinations (114 people). These NEET people are altogether 756 capita from the total numbers while the number in the rest of the five categories is only 108 young people who were not in employment, education or training.

The figures show those categories within the young people at a considerable risk apart from the fact that the NEET group itself indicates a very vulnerable population in the society. These are those who have secondary education levels and those who have the lowest qualification level or do not even have that.

The next diagram shows the sizes of proportions selected those who are at a considerable risk whom should be given even more attention to.

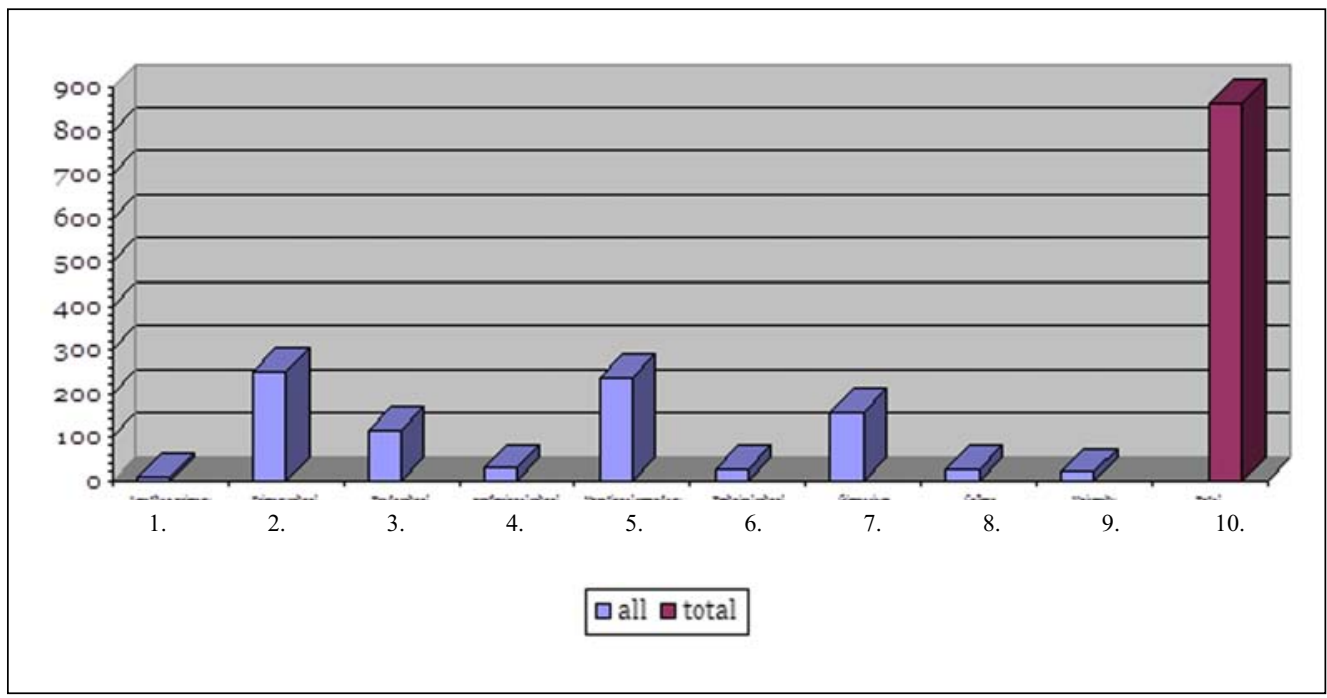

FigURE 9 Educational achievements within the NEET group in Szeged according to the ED's data (capita). [Legend: 1. Less than primary, 2. Primary school, 3. Trade school, 4. Professional school, 5. Vocational secondary school, 6. Technical school, 7. Gimnasium, 8. College, 9. University, 10. Total] (Source: SÁNTA 2016b)

On the diagram it can be well observed the different categories, and that there are three, or even four groups whose members are at a considerable risk.

The highest value is constituted by those who have only primary education. This is $28.93 \%$ within the total NEET population. They are followed by those who have vocational secondary 
education with $27.45 \%$. The third place is for those who have grammar school education, altogether $18.05 \%$. Finally, come those who have trade school education with $13.19 \%$. These are altogether 756 young NEET people which was $87.5 \%$ of the total NEET group in Szeged in 2011.

It should be recalled in a brief comparison that according to the CSO's data those young NEET people are the most vulnerable who have the lowest qualification level (or even less) and those who have secondary graduation. That is, comparing the data from the two informants they correlate with each other emphasised the greatest risk factor group, those who have the lowest qualification. Furthermore, one of the secondary categories is defined by the CSO as secondary graduation. However this category is divided by the ED into two different categories distinguishing vocational secondary school and grammar school education (the technical school education does not play important role). Inasmuch the two categories (the vocational secondary school and grammar school education which categories provide school leaving examination) are added then those data exhibit a high degree of similarity with the CSO's related data.

\subsection{Analysis of NEET data based on a comparison of data from the two informants}

Finishing the main part of this study the statistical data on the size of the NEET group in Szeged will be compared based on the two informants, the Central Statistics Office's and the local Employment Department's database. This procedure will prove the hypothesis stated at the beginning of this paper: Because the methodological procedures of the two informants (CSO and ED) differ from each other therefore, it is presumable that the rate of the NEET group is higher than the rate of the officially registered NEET group. Data in two summary tables and the corresponding figures will underpin the method of proof.

The first table relating to this method (Table 10) confirms and presents the data of the NEET groups in Szeged in 2011 according to the CSO and the ED. Within the data, just as usual, the gender breakdowns are shown as well as the last column on the right hand side show the numbers of the total NEET groups according to the two informants' data.

\begin{tabular}{|l|c|c|c|}
\hline \multicolumn{1}{|c|}{ Sampling dates } & Men & Women & Total \\
\hline October/2011. (CSO) & 1,037 & 914 & 1,951 \\
\hline December/2011. (ED) & 462 & 402 & 864 \\
\hline Non-Registered (capita) & $\mathbf{5 7 5}$ & $\mathbf{5 1 2}$ & $\mathbf{1 , 0 8 7}$ \\
\hline Non-Registered (\%) & $\mathbf{5 5 . 4 5 \%}$ & $\mathbf{5 6 . 0 2 \%}$ & $\mathbf{5 5 . 7 2 \%}$ \\
\hline
\end{tabular}

TABLE 10 Summary table about the total NEET population in Szeged and their gender breakdowns according to the CSO's and ED's data (capita/\%). (Source: SÁNTA 2016b)

As can be observed from Table 10 the size of the NEET group in Szeged were 1,951 young people in 2011 according to the census' data. It is divided by gender that there were 1,037 men and fewer women in the group, they were 914.

In the same year 864 young people registered at the ED as NEET. The gender breakdown was as follows: 462 men and 402 women. 
In the data of the gender breakdowns the same tendency can be observed: the number of NEET men is higher than the number of NEET women. Despite the fact that the number of men in the total population of Szeged and in the whole 15-24 age group as well is lower than the number of women.

In addition from the comparison of the NEET groups reveal that 1,087 young people lived in Szeged in 2011 who were not in employment, education or training, that is they were NEET but they did not register as job seekers at the ED. That means 1,087 young NEET people (575 men and 512 women) had not even been on the radar of the Employment Department in 2011!

Figure 10 shows these numbers in bar charts.

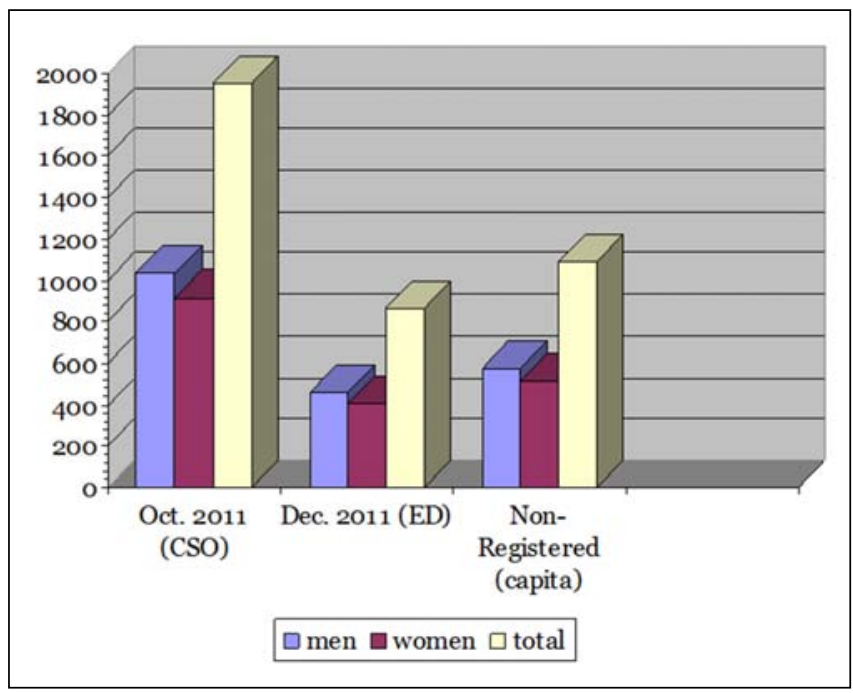

FigURE 10 Summary diagram about the total NEET population in Szeged and their gender breakdowns according to the CSO's and ED's data (capita). (Source: SÁNTA 2016b)

From the previous data expressed in percentage it can be seen that within the total NEET group in Szeged $55.72 \%$ of young NEET people did not register at the ED in 2011. That means in effect there is no information about more than half of the total NEET group! Distribution by gender $55.45 \%$ of men and $56.02 \%$ women are unknown.

In the last table a further breakdown could be applied by which the CSO's data gave the opportunity. As it was mentioned earlier that the total NEET group in Szeged derived from the CSO's census data was dividable into two groups: job-seekers and non-job-seekers. These data is compared with the data of the NEET group from the ED database as the last table shows.

\begin{tabular}{|c|c|c|c|}
\hline \multicolumn{1}{|c|}{ Sampling dates } & Job-seekers & Non-job-seekers & Total \\
\hline October/2011. (CSO) & 909 & 1,042 & 1,951 \\
\hline December/2011. (ED) & & & 864 \\
\hline
\end{tabular}

TABLE 11 Summary table about the total NEET population in Szeged according to the CSO's and ED's data (capita). (Source: SÁNTA 2016b) 
According to the data of the CSO, in 2011 there were 909 young people in NEET who actively looked for a job. However, more than this, 1,042 young people in NEET somehow decided not to exercise this option. It is very interesting to see that the number of those young NEET people who were job-seekers in the CSO's database is almost the same with the number of those NEET people who registered as a job seeker at the Employment Department. The difference in total is 45 people. That is, the assumption may have a probability that a significant proportion of those young NEET people who were identified as job-seekers according to the CSO's data registered at the Employment Department in order to facilitate their own situation. However, 1,042 young NEET people did not choose that way. This research is not able to provide an answer for this reason.

The last diagram (Figure 11) shows the above data in bar charts. The four diagrams present the gender breakdown as well.

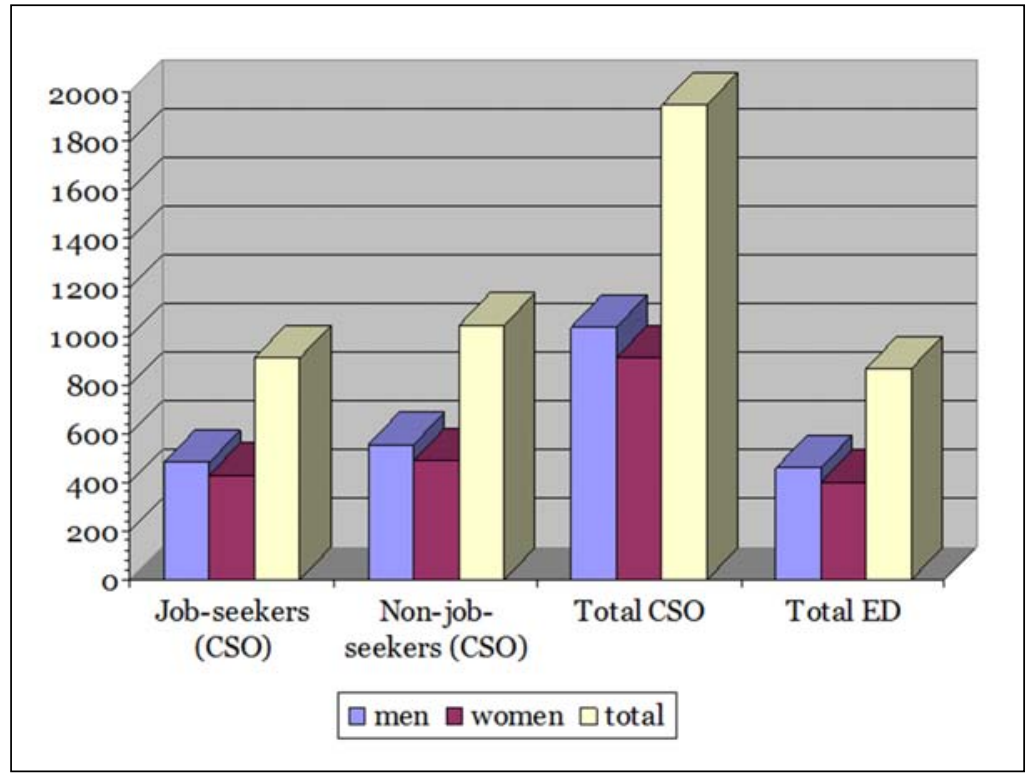

FIGURE 11 Summary diagram about the total NEET population in Szeged according to the CSO'S and ED’s data (capita). (Source: SÁNTA 2016b)

The charts illustrate that the rate of job-seekers NEET is $46.59 \%$ within the total NEET group in Szeged while the rate of non-job-seekers is higher, $53.41 \%$. In case if the registered NEET population by the ED is compared with the job-seekers NEET population according to the CSO the following can be said: $46.59 \%$ of the total NEET group was those who actively looked for a job based on the CSO's data while the rate of the registered young NEET people based on the ED's data compared with the total NEET population was $44.28 \%$. The difference in total is $2.31 \%$.

These data and the process, I believe, proved that the hypothesis was correct that the rate of the NEET group in Szeged was higher (even significantly higher) than the rate of the officially registered NEET group in 2011.

Description of the margin of errors and the conclusion of the research are presented in the last chapter. 


\section{Conclusion}

The objective of the research was to determine the size of the NEET group in a Hungarian city, called Szeged based on two informants and their statistical data from 2011.

One of them was the Central Statistics Office (CSO). From this database the census data were derived. In summary it can be claimed that the size of the NEET group in Szeged compared with the total 15-24 age group is high; it was $7.31 \%$ of the total age group in 2011 in the city. Within the NEET group the rate of men is higher (8.11\%) than the rate of women (6.57\%) apart from the fact that the size of men is considerably lower than the size of women in the total age group.

Furthermore, it is eyecatching that within the NEET group the rate of the non-job-seekers is higher than the job-seekers $(1,042-909 ; 53.40 \%-46.59 \%)$ which is definitely justify further social policy research that was mentioned above.

If the educational achievements are under detailed analysis it can be said that within the NEET group there are two sub-groups who are truly vulnerable apart from the fact that the young people in the whole NEET group are in a considerable danger. Solving the problem of young people who have very low qualifications or even who do not have any qualifications and of those who only have secondary graduation bears no delay. In this analysis it was also detectable that the rate of men in NEET is higher than of women even within men there are more who do not search for any jobs regardless of the obtained education level (53.51\%). There was only one sub-group where in the rate of job-seekers men were higher than of non-job-seekers men. They were those who had professional diploma without school leaving examination. In this sub-group 56.01\% of men were actively job-seekers in the NEET group. However, in this sub-group the rate of women were higher, those who decided for some reasons that they would not look for jobs $(57.14 \%)$. On the other hand, within the group those members who have the highest qualification, they can be men or women, there are more who were actively searching for jobs.

The other informant was the Employment Department of the Csongrád County Government Office (ED). From the ED's data the following can be said relating to the NEET group in Szeged.

The ED's database held 864 registered young people who were NEET in 2011. The men's rate within the total NEET population was $53.47 \%$ while the women's rate was $46.53 \%$. So the ED's database held proportionally less young NEET people in the city but like the CSO's data, here can be said as well that the number of men is higher than the number of women.

The ED's database provided an opportunity to follow the development of the NEET rate in the next years. Although these data are informative because only those population can be presented who were registered by the ED. Compared the baseline data with the data from 2012 it can be observed that the rate of the NEET group was grown. The men's rate within the total NEET population increased by $13.26 \%$ and the women's rate also increased but only by $12.04 \%$. However, in the rate of the total NEET group a significant decrease was observable in 2013. The number of the total NEET group decreased by $28.12 \%$ compared it with the previous year and within this the men's rate showed a significant reduction, and in 2013 for the first time the women's rate was higher than the men's rate. Within the total NEET population the men's rate showed a $37.48 \%$ decrease while the decrease of the women's rate was only $17.07 \%$. In 2014 the men's rate drastically increased again while the women's rate compared it with the previous year decreased. The men's rate increased in this year with $9.9 \%$ while the women's rate decreased with $10.56 \%$. Thus the total number of NEET decreased with $0.42 \%$ in 2014 .

The ED's database provided a more detailed breakdown as for the educational achievements. The research presented those categories wherein the young NEET people are at a considerable risk. 
The most vulnerable are those who have the lowest qualification. They reached $28.93 \%$ within the total NEET population. They are followed by the group whose members have vocational secondary school level (27.45\%). At the third place are those who have grammar school level which provide a school leaving examination but does not a profession (18.05\%). Closing the line those stand who have trade school level $(13.19 \%)$. They are altogether 756 young people that was $87.5 \%$ of the total NEET group in December 2011.

The hypothesis was that because the methodological procedures of the two informants (CSO and ED) differ from each other therefore, it is presumable that the rate of the NEET group is higher than the rate of the officially registered NEET group. This was justified by the comparison of the data of the two informants.

According to the census data in 2011 the size of the NEET population in Szeged was 1,951 young people aged between 15 and 24. The gender breakdown within the NEET group was: 1,037 men and 914 women.

In the same year only 864 young people registered at the ED as NEET; amongst them there were 462 young men and 402 young women.

Based on the gender breakdown the same tendency can be observed when the data of the two informants compared. That is, the rate of young NEET men is higher than the rate of young NEET women in the research year. Despite the fact that the number of men in the total population of Szeged and in the whole 15-24 age group as well is lower than the number of women.

It became clear during the research that 1,087 young people lived in Szeged in 2011 who were not in employment, education or training that is they were in NEET but they did not register as job seekers at the ED. That means 1,087 young NEET people (575 men and 512 women) had not even been on the radar of the Employment Department in 2011!

According to the data of the CSO, in 2011 there were 909 young NEET people who actively looked for a job. However, more than this, 1,042 young NEET people somehow decided not to exercise this option. It is very interesting to see that the number of those young NEET people who were job-seekers in the CSO's database is almost the same with the number of those who registered as a job seeker at the Employment Department. The difference in total is 45 people. In case if the registered NEET population by the ED is compared with the job-seekers NEET population according to the CSO the following can be said: $46.59 \%$ of the total NEET group was those who actively looked for a job based on the CSO's data while the rate of the registered NEET people based on the ED's data compared with the total NEET population was $44.28 \%$. The difference in total is $2.31 \%$. That is, the assumption may have a probability that a significant proportion of those young NEET people who were identified as job-seekers according to the CSO's data registered at the Employment Department in order to facilitate their own situation. However, 1,042 young NEET people did not choose that way!

It should be recalled in a brief comparison that according to the CSO's data those young NEET people are the most vulnerable who have the lowest qualification level (or even less) and those who have secondary graduation. That is, comparing the data from the two informants they correlate with each other emphasised the greatest risk factor group, those who have the lowest qualification. Furthermore, one of the secondary categories is defined by the CSO as secondary graduation. However this category is divided by the ED into two different categories distinguishing vocational secondary school and grammar school education (technical school education did not play important role). Inasmuch the two categories (the vocational secondary school and grammar school education which categories provide school leaving examination) are added then those data exhibit a high degree of similarity with the CSO's related data. 
It can be said about both informants that their statistical data relating to the NEET group move between certain margin errors. That means the presented data in this paper are not exact data but in any case they are between the statistical margins of errors.

Furthermore, between the two surveys, as was mentioned earlier, a few months pasted, and during this time the data might have been changed. But this can be almost certain that the NEET population in Szeged did not decrease by 1,087 people between October and December in 2011. And this statement can be sustainable also together with the fact that the ED does not analyse the whole 15-24 age group however its data was given for the 17-24 population. Although the NEET group is not a homogeneous community, an everchanging company, whose members can be very vulnerable or not at risk at all (Coles et al. 2010), the data show that many are in the first category.

According to empirical experiences and many research documents demonstrate that to be part of the NEET group is not satisfying even this is a highly dangerous condition and will cause serious effect on our future. Therefore I find essentially important to continue researches on the NEET group.

\section{REFERENCES}

Audit COMMISSION (2010): Against the odds. Reengaging young people in education, employment or training. London, Audit Commission Publishing Team.

BAuer, Béla - Szabó, Andrea (eds.) (2011): Arctalan (?) nemzedék. Budapest, Nemzeti Család- és Szociálpolitikai Intézet.

Coles, Bob - Godfrey, Chrisitne - Keung, Antonia - Parott, Steven - Bradshaw, Jonathan (2010): Estimating the lifetime cost of NEET: 16-18 year olds not in Education, Employment or Training. Department of Social Policy and Social Work and Department of Health Sciences, The University of York.

European COMMISSION (2012): EU Youth Report. Belgium, Publications Office of the European Union.

EUROPEAN COMMISSION (2013): Youth Unemployment. www.ec.europa.eu/europe2020/pdf/themes/ 21_youth_unemplyment.pdf. Last download: 03. 03. 2015.

European Commission. (2014): Youth Unemployment. http://www.ec.europa.eu/europe2020/pdf/ 22_youth_unemployment_02.pdf. Last download: 09.04. 2015.

GÁBOR, KÁLMÁN (2012): Válogatott ifjúságszociológiai tanulmányok. Szeged, Belvedere Meridionale. JANCSÁK, CSABA (ed.) (2011a): Az Európai fiatalok világa a 21. század elején. Szeged, Belvedere Meridionale.

JANCSÁK, CsABA (2011b): Az ifjúságkutatás nemzetközi tendenciái. In Bauer, Béla - Szabó, Andrea (eds): Arctalan (?) nemzedék. Budapest, Nemzeti Család- és Szociálpolitikai Intézet.

JANCSÁK, CSABA (2013): Ifjúsági korosztályok korszakváltásban. Budapest, Új Mandátum Kiadó.

JANCSÁK, CSABA - KÁTAI, GÁBOR (2013): Youth Services Participation of Youth. Youth Policy in Hungary (2006-2012). Belvedere Meridionale vol. 25. no. 4. 88-100.

KÁTAI, GÁBOR (2006): Gondolatok az ifjúságpolitikáról és eszközeiről. Szeged, Belvedere Meridionale.

Központi Statisztikai Hivatal: Fogalomtár. http://www.ksh.hu/docs/hun/agrar/html/fogalomtar.html\#m. Last download: 19. 04. 2015. 
NAGY, ÁdÁm (ed.) (2008): Ifjúságügy. Budapest, Új Mandátum Kiadó.

Nemzeti Foglalkoztatási Szolgálat. Fogalommagyarázat. http://www.afsz.hu/fogalom_magyarazat. Last download: 09. 04. 2015.

OECD (2013): The OECD Action Plan for Youth. http://www.oecd.org/newsroom/Action-plan-youth.pdf. Last download: 06. 11. 2014.

OECD (2014): Society at Glance 2014: OECD Social Indicators. OECD Publishing. http://dx.doi.cor/ 10.1787/soc_glance-2014-en. Last download: 06. 11. 2014.

OECD (2015): Youth not in employment, education or training (NEET). https://data.oecd.org/ youthinact/youth-not-in-edication-or-employment-neet.htm. Last download: 09. 04. 2015.

SÁntA, TAmÁs (2016a): Youngsters Who Are Not in Employment, Education or Training (About the NEET in a Hungarian Perspective). Belvedere Meridionale vol. 28. no. 2. 120-131. http://www.belvedere-meridionale.hu/wp-content/uploads/2016/02/09_Santai_Belvedere\%20 Meridionale_2016-2_pp120-131.pdf. Last download: 01. 05. 2016.

SÁNTA, TAMÁs (2016b): NEET-Kutatás - Szegedre vonatkozó statisztikai adatok tükrében. In Jancsák Csaba - Krémer András (eds.): Kisvárosi Fiatalok, Kisebbségek, Új Sebezhetőségek. Szeged, Belvedere Meridionale. 111-146.

Sissons, PAUl - Jones, Katy (2012): Lost in transition? The changing labour market and young pople not in employment, education or training. The Work Foundation. London, Part of Lancaster University.

Spielhofer, Thomas - Benton, Tom - Evans, Kelly - Featherstone, Gill - Golden, SARAH Nelson, Julie - Smith, Paula (2009): Increasing Participatio: Understanding Young People who do not Participate in Education or Training at 16 and 17. Department for Children, Schools and Families. National Foundation for Educational Research. Nottingham, DCSF Publications. http://www.dera.ioe.ac.uk/11328/1/DCSF-RR072.pdf. Last download: 30. 05. 2015.

Szeged Megyei Jogú Város Önkormányzata: Helyi Esélyegyenlöségi program 2013-2018. (HEP) http://www.szegedvaros.hu/.../3111-szeged-helyi-eselyegyenlosegi-program-2013-2018. Last download: 20. 05. 2014. 